4th Global Business Research Congress, May 24-25, 2018, Istanbul, Turkey.

\title{
ONLINE SHOPPERS: EFFECTS OF INERTIA AND SATISFACTION ON ONLINE SHOPPING LOYALTY
}

\author{
DOI: 10.17261/Pressacademia.2018.905 \\ PAP- V.7-2018(58)-p.311-315
}

\section{Cansu Gokmen Koksal}

Gebze Technical University, 41400, Kocaeli, Turkey.

ckoksal@gtu.edu.tr, ORCID: 0000-0001-9139-0451

To cite this document

Koksal, C. G. (2018). Online shoppers: effects of inertia and satisfaction on online shopping loyalty. PressAcademia Procedia (PAP), V.7, p.311-315.

Permemant link to this document: http://doi.org/10.17261/Pressacademia.2018.905

Copyright: Published by PressAcademia and limited licenced re-use rights only.

\section{ABSTRACT}

Purpose- Online shopping, which is an important reflection of the fundamental changes that have taken place in information and communication technologies, has become an indispensable part of daily life of consumers and businesses. The loyalty of online consumers will be explained with consumer inertia and consumer satisfaction concepts.

Methodology- In order to achieve this goal, a research was implemented by using face to face survey method on online shopping consumers.

Findings- Kuo, Hu and Yang (2012) have indicated that both consumer inertia and satisfaction positively influence re-purchase intention and loyalty.

Conclusion- In this context, the results to be obtained within the context of the study are expected to present a different perspective to the factors that influence the loyalty of Turkish online shoppers. It is thought that the research is important in terms of enabling comparison and discussion of the results obtained in other studies in the literature.

Keywords: Satisfaction, loyalty, consumer inertia, consumer behavior online shopping.

JEL Codes: L81, M31, M39

\section{ONLINE ALIŞVERIŞÇiLER: ATALET VE MEMNUNIYETIN ONLINE ALIŞVERIŞ SADAKATINE ETKISi}

\section{ÖZET}

Amaç - Bilgi ve iletişim teknolojilerinde meydana gelen köklü değişikliklerin önemli bir yansıması olarak online alışveriş tüketicilerin günlük yaşamlarının, işletmelerin ise faaliyetlerinin vazgeçilmez bir parçası haline gelmiştir. Online alışveriş yapan tüketicilerin sadakati, tüketici ataleti ve tüketici memnuniyetleri konseptleri ile açıklanmaya çalışılacaktır.

Yöntem- Bu amaca ulaşmak için online alışveriş yapan tüketicilere yüz yüze anket yöntemi ile bir uygulama gerçekleştirilecektir.

Bulgular- Kuo, Hu ve Yang (2012), tüketici ataleti ve memnuniyetinin; tüketicilerin online alışverişe yönelik alışveriş niyeti ve sadakati üzerinde olumlu etkilerini olduğunu ortaya koymuştur.

Sonuç- Bu bağlamda çalışma kapsamında elde edilecek sonuçların, Türk online alışverişçilerin sadakatlerinde etkili olan unsurlara farklı bir bakış açısı sunacağı düşünülmektedir. Araştırmanın, literatürdeki diğer çalışmalar doğrultusunda elde edilen sonuçların kıyaslanmasına ve tartışılmasına olanak sağlaması bakımından önemli olduğu düşünülmektedir.

Anahtar Kelimeler: Memnuniyet, sadakat, tüketici ataleti, tüketici davranışı, online alışveriş. JEL Kodları: L81, M31, M39

\section{GíRiş}

Bilgi ve iletişim teknolojilerinde meydana gelen gelişmelerin etkilerini gösterdiği alanların biri de perakendecilik sektörüdür. İnternetin ticari alanda kullanımının artması, tüm sektörlerde olduğu gibi perakendecilik sektörünü de etkilemiş ve 2000'lerde önemli değişimler geçiren perakendecilik sektörü elektronik mağaza(e-mağaza), elektronik alışveriş (e-alışveriş) ve elektronik perakendecilik (e-perakendecilik) konseptlerini literatüre kazandırmıştır. Online perakendecilik; geleneksel iletişimdeki medyanın aksine, çift yönlü, karşılıklı bir iletişim platformu sunarak, tüketicilerin perakendecilere geri bildirimde bulunmasına, istek ve şikayetlerini anında perakendecilere ulaştırmasına olanak tanımaktadır. Bu konseptler bağlamında hayatımıza giren online alışverişin ülkemizde sahip olduğu payın da giderek arttığı görülmektedir (Bilgen ve Zoghi, 2017). Tüik Hane halkı Bilişim Teknolojileri Kullanım Araştırması (2017) Türkiye 'de yaklaşık 48 milyon internet kullanıcısının bulunduğunu ve internet üzerinden alışveriş yapan ürün satın alan veya hizmet siparişinde bulunan 16-64 yaş grubunda yer alan tüketicilerin toplam kullanıcılara oranının \%25 olduğunu ortaya koymaktadır. Öte yandan Türkiye'deki internet 
kullanıcılarının 1 aylık etkinlikleri incelendiğinde, internet kullanıcılarının \%43'ü tarafından online ürün ve satın alımların yapılması bulgusu (Marketing Türkiye, 2017), Forsythe ve Shi 'nin (2003) internetin en hızlı büyüyen kullanımının alışveriş olduğu yargısını destekler niteliktedir.

Web sayesinde tüketiciler ürün ve hizmetlere düşük fiyatla (Bakos,1997), karşılaştırma yaparak ve kişiye özel ürün ve hizmetlere her yerden ve her an ulaşabilme imkânına sahip olmuştur. Online perakendecilik sayesinde pazarlamacılar daha az masrafla, işlem maliyetlerini ve masraflarını azaltıp (Shankar vd., 1999), daha çok tüketiciye, düşük fiyatlarla ulaşarak (Peterson, 1998), coğrafi kısıtları ortadan kaldırmış (Wang vd., 2002); yeni perakendecilik modelleri ile satışlarını arttırarak, tüketicilerle olan ilişkilerini güçlendirmiştir. Tüketiciler evlerinden çıkmadan, hızlı bir şekilde web sitelerini ziyaret ederek ürünleri inceleyip ve sipariş verme imkanına sahip olmuştur (Burke, 1997; Forsythe vd., 2006). Online perakendecilikte, perakendeciler daha fazla ürün dizisini aynı anda tüketicilerine sunarak sergileme imkanına sahip olmuştur (Alba vd., 1997; Donthu ve Garcia 1999; Forsythe vd., 2006). Online alışverişin sunduğu bu avantajların tüketicilerin davranışsal niyetlerinde olumlu yönde katkıda bulunduğu çeşitli araştırmalar çerçevesinde sıkça ele alındığı görülmektedir (Örneğin: Yang ve Peterson, 2004; Wolfinbarger ve Gilly, 2003). Öte yandan büyük küçük ayrımı olmaksızın ürün ve hizmetlerini internet üzerinden sunan işletmelerin sayıca yüksekliği, tüketicilerin tercihlerini nasıl etkilediği de ayrı bir araştırma olduğu ifade edilebilir. Peki gerçekten tüketicilerin online alışveriş yaptıkları işletmelere duydukları sadakat, o işletmeye duydukları memnuiyetten mi etkilenir yoksa bu davranış bir alışkanlığın ve değiştirme sonucunda katlanılacak (zaman, maliyet gibi) unsurlardan kaçmak amaçlı bir tekrarın sonucu mudur? Online alışveriş ile ilgili yapılan çalışmalar, elektronik hizmet kalitesi, marka, memnuniyet, alışveriş niyeti gibi birçok unsurun tüketicilerin sadakatlerinde etkili olduğunu desteklemektedir. Bu çalışmalardan farklı olarak özellikle Türkiye bağlamında online alışveriş yapan tüketicilerin sadakatlerinde memnuniyetin mi yoksa tüketici ataletinin mi baskın olduğu ortaya çıkarılması amaçlanmaktadır.

\section{LITERATÜR INCELEMESI}

Oliver (1999) müşteri sadakatini "Tercih edilen bir ürün veya hizmetin gelecekte de satın alınacağına dair güçlü bir bağlılık olarak tanımlamıştır. Müşteri sadakatindeki gelişmeler, özellikle mevcut müşterilerin elde tutulmasında işletmelere sağladığı avantajlar sebebiyle pazarlama stratejisinde önemli bir odağı olmuş ve birçok araştırmacının da sıkça ele aldığı bir konsepte dönüşmüştür (Han, Kim ve Kim, 2011). Özellikle perakendecilikte meydana gelen gelişmeler ile yapısı ve dinamikleri tamamen farklılaşan alışveriş olgusu için de sürekliliğin sağlanmasının önemi büyüktür. En hızıı büyüyen kanallardan biri olarak online alışverişin işletmelere ve tüketicilerine sağladığı faydalar zamanla işletmeler arasında yoğun rekabet ortamının da oluşmasına neden olmuştur. Bugün benzer ürün ve hizmetleri online ortamda tüketicilere sunan işletmelerin yeni müşterileri çekmesi ve mevcut olanları elde tutmasının maliyeti artmıştır. Bu sorun da özellikle online alışveriş ortamında da müşteri memnuniyetinin ve sadık müşterilerin işletmeler için en önemli varlıklar arasında değerlendirilmesine yol açmıştır (Gefen, 2003; Anderson ve Swaminathan, 2011). Sadık müşterinin daha yüksek fiyatı ödemeye razı olması, yaşanan olumsuzlukları daha fazla tolere etmesi bakımından işletmelerin karlarında da olumlu katkılarda bulunmaktadır. Bunun yanı sıra Srinivasan, Anderson ve Ponnavolu'nun (2002) yaptığı araştırmada e-perakendeciye sadık olan müşterilerin, e-perakendeci hakkında olumlu şeyleri söylemeye daha hevesli olduğu bulgusuna ulaşılmıştır. Bu da memnun olan müşterilerin etrafındaki potansiyel müşteri olma yönünde potansiyel olanları da olumlu yönde etkilemelerine katkıda bulunacağını göstermektedir. Aldığı hizmetlerden veya ürünlerden memnun olan bir müşterinin, işletmeyi çevresindekilere önermesi, işletmenin diğer müşterilere cazip gelmesine ve olumlu bir imaja sahip olmasına katkıda bulunmaktadır (Zeithaml, Parasuraman ve Malhotra, 2000). Literatürde birçok çalışmada müşterilerin sadakatlerini etkileyen ve açıklayan birçok unsurun ele alındığı ve ele alınmaya da devam ettiği görülmektedir. Bu bağlamda yapılan çalışmalarda müşteri sadakatinin öncülleri arasında en sık ele alınan konsept müşteri memnuniyeti olsa da sadakat tüketicilerin ataletleri sonucunda da meydana gelebilir (Wu, 2011). Atalet kavramı doğrultusunda âtıl tüketiciler, yeni satın alım kararlarından kaçınan, rutin alışkanlıkları doğrultusunda ürün ve hizmet satın aldığı tercihleri değiştirmeyen, fiyat karşılaştırmalarından sakınan bireyler olarak açıklanmıştır (Goh, Jiang, Hak ve Tee, 2016). Bu bağlamda da ataletin sonucunda tüketicilerin sadakatlerinin olabileceği tartışılmaya başlanmıştır (Örneğin: Anderson ve Srinivasan, 2003). Buna ek olarak, Kuo, Hu ve Yang'ın 2012 yılında yapmış oldukları çalışma bulguları; tüketici ataleti ve memnuniyetinin, tüketicilerin online alışverişe yönelik alışveriş niyeti ve sadakati üzerinde olumlu etkilerini olduğunu ortaya koymuştur. Ayrıca online perakendecilik literatüründe çok sayıda çalışma müşteri memnuniyeti ve sadakat arasındaki varsayılan ilişkiyi ampirik olarak da desteklemiştir (Örneğin: Sadeh et al., 2009; Anderson et al. 2011). Bu unsurların doğrultusunda çalışma kapsamında aşağıdaki hipotezler geliştirilmiştir:

H1: Tüketici ataleti, tüketicilerin online alışveriş sitesine olan sadakatlerini olumlu olarak etkilemektedir.

H2: Tüketicilerin memnuniyeti, tüketicilerin online alışveriş sitesine olan sadakatlerini olumlu olarak etkilemektedir

\section{VERI VE YÖNTEM}

Çalışmanın amacı; tüketicilerin online alışveriş yaptıkları alışveriş sitesinden duydukları memnuniyetleri ile tüketicilerin ataletlerinin, alışveriş yaptıkları online alışveriş sitesine olan sadakatlerine etkilerinin ortaya çıkarılmasıdır. Özellikle Türk online alışverişçilerin sadakatlerinde baskın olan unsurun memnuniyet mi yoksa atalet davranışı mı sorusuna yanıt bularak tartışmak amaçlanmıştır. Amaçlar doğrultusunda çalışmanın ana kütlesini oluşturan online alışveriş yapan kişilere yüz yüze anket uygulaması yapılmıştır. Çalışmadaki tüm ölçekler $5^{\prime}$ li Likert olup 1=kesinlikle katılmıyorum 5=kesinlikle katılıyorum olarak değerlendirilmiştir Online alışveriş yapan tüketicilerin memnuniyetlerinin ölçümünde Anderson ve Swaminathan'nun (2011) çalışmasından; tüketicilerin ataletlerinin ölçümünde Kuo, Hu ve Yang'in (2012) çalışmasından ve tüketicilerin online alışveriş sitesine duydukları sadakatin ölçümünde Wu'dan (2011) uyarlanan online alışveriş sadakati ölçeği çalışma için uyarlanmıştır. 20 kişilik bir grup üzerinde pilot test çalışması uygulanarak, elde edilen sonuçlar doğrultusunda çeşitli düzenlemeler yapılarak, anket formu nihai haline getirilmiştir. Çalışmanın örneklemini online alışveriş yapan kişiler oluşmaktadır ve çalışma kapsamında kolayda örnekleme yöntemi tercih edilmiş olup, 137 katılımcıdan elde edilen veriler SPSS 21 programı kullanılarak değerlendirilmiştir. 


\section{BULGULAR}

Araştırmaya katılan katılımcıların yaklaşık \%60'ının 26-30 yaş arası, \%74'ünün kadın, \%77.4'ünün lisans düzeyinde eğitimi olan ve \%82'sinin öğrenci olduğu gözlemlenmiştir. Katılımcıların kaç yıldır online alışveriş yaptıkları ve alışveriş yapma sıklıkları ile ilgili sorular da araştırmada kapsamında yöneltilmiş olup buna göre: Katılımcıların yaklaşık \% 43'ünün (58 kişi) 2 ile 5 yıl arası zamandır online alışveriş yaptığı; yaklaşık \%33'ünün (45) ise 5 yıl ve üstü zamandır online alışveriş yaptığı; \%27.7'sinin (83 kişi) 2 ile 5 yıl arası zamandır online alışveriş yaptığı; \%20.4'ünün (28 kişi) 1 ile 2 yıldır online alışveriş yaptığı ve \%4.4.'ünün (6 kişi) 1 yıldan az bir süredir online alışveriş yaptığı görülmüştür. Katılımcıların online alışveriş yapma sıklıkları incelendiğinde ise; yaklaşık \%48'inin (65 kişi) ayda bir kez alışveriş online yaptığı; \%32.8'inin (45 kişi) ayda birden fazla online alışveriş yaptığı; \%15.3'ünün ise (21 kişi) yılda bir kez online alışveriş yaptığı görülmüştür.

Anketin ikinci bölümünde yer alan 11 önerme temel bileşenler analizi çerçevesinde gerçekleştirilen faktör analizi sonucunda 3 faktör altında toplanmıştır. Korelasyon, güvenirlik analizi ve çoklu regresyon analizi de hipotezlerin analizi kapsamında yapılmıştır. Illk adımda ölçeklerin yapı geçerliliğini test etmek için temel bileşenler analizi ve "varimaks" eksen döndürmesi tekniği kullanılarak yapılan keşfedici faktör analizi sonuçları ve güvenilirlik analizi sonuçları Tablo 1'deki gibi özetlenmektedir. Faktör analizi sonucunda sadakat faktörünün Kaiser-MeyerOlkin(KMO) örneklem yeterlilik değerinin 0.709 olduğu ve açılanan kümülatif varyans derecesinin \%59.47; atalet ve memnuniyet faktörlerinin Kaiser-Meyer-Olkin (KMO) değeri, 0,692, açılkanan kümülatif varyans derecesi ise \%73.62 olarak belirlenmiştir. Hesaplanan değerler önerilen \%60 değerinden büyük (Hair vd., 1998: 88), Bartlett Küresellik Testinin anlamlılık düzeyleri ise ( $p=0,000$ ) olarak hesaplanmıştır Bu bağlamda araştırmada kullanılan verinin büyüklüğünün faktör analizi yapmak için yeterli olduğu tespit edilmiştir. Sadakat boyutunun altında yer alan maddenin faktör yükü 0.40 `ın altında olduğu gerekçesiyle ölçekten çıkartılarak faktör analizi tekrarlanmıştır.

Tablo 1: Faktör Analizi ve Güvenilirlik Analizi Sonuçları

\begin{tabular}{|l|c|c|c|c|}
\hline Faktörler & $\begin{array}{c}\text { Kaiser-Meyer-Olkin } \\
\text { (KMO) }\end{array}$ & Bartlett Küresellik Testi & $\begin{array}{c}\text { Cronbach } \\
\text { Alpha }\end{array}$ & $\begin{array}{c}\text { Madde } \\
\text { sayısı }\end{array}$ \\
\hline Atalet &, 692 &, 000 &, 690 & 3 \\
\hline Memnuniyet &, 692 &, 000 &, 897 & 3 \\
\hline Sadakat &, 709 &, 000 &, 750 & 4 \\
\hline
\end{tabular}

Tüm ölçeklerin güvenilirliğini değerlendirmek için “Cronbach Alpha” katsayıları hesaplanmış ve atalet faktörü dışında iki ölçeğin de ölçeğin güvenilirliğinin 0.80 'in üzerinde olduğu görülmüştür. Buna göre de belirlenen faktörlerin güvenilir olduğunu söylemek mümkündür.

Tablo 2. Ortalamalar ve Korelasyon Analizi Tablosu

\begin{tabular}{|l|c|c|c|c|c|}
\hline & Ortalama & $\begin{array}{c}\text { Standart } \\
\text { Sapma }\end{array}$ & 1 & 2 & 3 \\
\hline Memnuniyet & 3,9440 &, 75577 & 1 & & \\
Atalet & 2,6322 &, 93870 &,- 012 & 1 & \\
Sadakat & 3,4842 &, 74373 &, $661^{* *}$ & $230 * *$ & 1 \\
\hline
\end{tabular}

${ }^{* *} p<0.01$ düzeyinde anlamlıdır.

Araştırma amacı kapsamında memnuniyet, atalet ve sadakat arasındaki ilişkinin ortaya konulması için yapılan ve Tablo 2'deki gibi özetlenen korelasyon analizi sonucunda faktörlerin birbirleriyle ilişkili oldukları gözlemlenmiştir.

Tablo 3: Çoklu Regresyon Sonuçları

\begin{tabular}{|l|c|c|c|c|}
\hline Model & \multicolumn{2}{|l|}{ Bağımlı değişken: Sadakat } & Hipotez \\
\hline Bağımsız Değişkenler & Beta & T değeri & P değeri & H1 Kabul \\
\hline Memnuniyet &, 664 & 12,95 & $0.00 * * *$ & H2 Kabul \\
Atalet &, 238 & 2,28 & $0.00 * * *$ & \\
\hline
\end{tabular}

$R=0.703, \operatorname{Adj} . R^{2}=0.486, R^{2}=0.494$, F değeri $=65,420,{ }^{* * *} p<0.001$

Çalışmada memnuniyet ve ataletin sadakat üzerindeki etkilerini belirlemek amacı ile yapılan çoklu regresyon analizi sonuçları Tablo 3'te verilmiştir. Tablo 4'teki regresyon analizi tablosunda analizin Anova tablosundan alınan p değerinin 0,000 olması regresyon analizinin anlamlı olduğunu göstermektedir. T istatistiği ve $p$ değerlerine bakıldığında 2 bağımsız değişkenin de tüketicilerin online alışveriş sitesine duymuş oldukları sadakat üzerinde anlamlı etkileri olduğu ve modele anlamlı katkı sağladığı görülmektedir. $\quad \beta$ değerlerine baktığımızda memnuniyetin $(\beta=0,664 p<0,001)$ sadakati anlamlı olarak etkilediği görülmektedir. Bunun yanında tüketicilerin atalet davranışlarının da $(\beta=0,238, p<0,011)$ sadakati anlamlı olarak etkilediği bulgusu elde edilmiştir. Sonuçlara göre öngörülen 2 hipotez de desteklenmiştir. Tablo 4'teki R2 değeri tüketicilerin online alışveriş sitesinden duydukları memnuniyetin, online alışveriş sitesine duyulan sadakat üzerinde önemli bir etkisinin olduğunu görülmektedir (R2=\%49). Yani, tüketicilerin online alışveriş yaptıkları siteye yönelik sadakatlerinde memnuniyetin $\% 66$ ’ lık, ataletin ise \%22 'lik bir etkisi olduğunu göstermektedir. 


\section{SONUÇ}

Araştırma kapsamında online alışveriş yapan tüketicilerin, alışveriş yaptıkları online alışveriş sitesine yönelik sadakatlerinde etkili olan atalet ve memnuniyet kavramlarının ele alınması ve karşılaştırılması amaçlanmıştır. Amaç doğrultusunda yapılan anket uygulaması sonucunda elde edilen bulgular literatürdeki sonuçlara paraleldir (Örneğin: Wu,2011; Kuo, Huo ve Yang, 2013; Goh, Jiang, Hak ve Tee, 2016; Anderson ve Srinivasan, 2003; Anderson ve Swaminathan, 2011; Nayebzadeh, Abdolvand, ve Khajouei, 2013, Kim ve Kang, 2016). Tüketicilerin alışveriş yaptıkları online alışveriş sitelerine olan sadakatlerinde memnuniyet unsuru kadar etkili olmasa da tüketicilerin atalet davranışlarıın da etkili olduğu sonucuna ulaşıımışır. Bu bağlamda online perakendecilerin, tüketicilerin alışkanlığa bağlı sadakatleri ile memnuniyete dayalı sadakatleri arasında ayrım yapmaları önemlidir. Özellikle ilerleyen yıllarda bu durumun uygulayıcılar açısından çeşitli olumsuz sonuçları da beraberinde getirebileceği hususu göz ardı edilmemelidir. Çünkü rakipleri tarafından sunulan çeşitli cazip teklifler ile bir zaman sonra tüketicilerin sadakatlerinin ve müşteri olma noktasındaki devamlııklarının değişebilme ihtimali söz konusu olabilir. 0 nedenle de işletmelerin öncelikle bu eylemsiz olarak değerlendirilen atıl tüketicileri de bilinçli olarak kendi ürün ve hizmetlerini, kanallarını tercih etmeleri sağlanarak memnun etmeleri ve böylelikle sadık hale getirmeleri sağlamalıdır.

Öte yandan çalışmanın çeşitli sınırıııkları da bulunmaktadır. 137 katııımıdan elde edilen bulguların, tüm online alışveriş yapan tüketicilere genellenmesi mümkün değildir. Ayrıca spesifik kategorilerde ürün ve hizmet sunan online perakendeciler için elde edilen sonuçlar farklılaşabilir. Bu nedenle belli alanda hizmet veren online perakendecilere yönelik tüketicilerin atalet ve memnuniyet düzeylerinin ele alınarak, bunların sadakat üzerindeki etkilerinin değerlendirilmesinin anlamlı sonuçların elde edilmesine katkıda bulunabileceği düşünülmektedir. Buna ek olarak tüketici ataletinin; memnuniyet ve sadakat arasındaki ilişkiye yönelik dolaylı etkilerinin gelecekteki çalışmalar bağlamında ele alınmasının değerli olduğu düşünülmektedir.

\section{KAYNAKLAR}

Alba, J., Lynch, J., Weitz, B., Janiszewski, R. L. Sawyer, A., Wood, S. (1997). Interactive home shopping: consumer, retailer, and manufacturer incentives to participate in electronic marketplaces. Journal of Marketing. 61, 38-53.

Anderson, R. E., Swaminathan, S. (2011). Customer satisfaction and loyalty in e-markets: a PLS path modeling approach. Journal of Marketing Theory and Practice, 19(2), 221-234.

Bakos, Y. (1997). Reducing buyer search costs: implications for electronic marketplaces, Management Science, 43(12).

Bilgen, I., Zoghi, F. S. (2017). A research on the impact of ewom source credibility and personal innovativeness on online shopping intention in Turkish customers. Journal of Management Marketing and Logistics, 4(2), 143-151.

Burke, R. R. (1997). Do you see what I see? The future of virtual shopping. Journal of the Academy of Marketing Science. 359-374.

Donthu, N., Garcia, A. (1999). The internet shopper. Journal of Advertising Research. 39(3), 52-58.

Forsythe, S. M., Shi, B. (2003). Consumer patronage and risk perceptions in Internet shopping. Journal of Business research, 56(11), 867875.

Gefen, D., Karahanna, E., Straub, D. W. (2003). Trust and TAM in online shopping: an integrated model. MIS quarterly, 27(1), 51-90.

Goh, S. K., Jiang, N., Hak, M. F. A., Tee, P. L. (2016). Determinants of smartphone repeat purchase intention among Malaysians: a moderation role of social influence and a mediating effect of consumer satisfaction. International Review of Management and Marketing, 6(4).

Han, H., Kim, Y., Kim, E. K. (2011). Cognitive, affective, conative, and action loyalty: testing the impact of inertia. International Journal of

Hair, J., Anderson, R. E., Tatham, R. L., Black, W. C. (1998). Multivariate data analysis (International 5th Edition). New York: Prentice-Hall, Inc. Hospitality Management, 30(4), 1008-1019.

Kuo, Y. F., Hu, T. L., Yang, S. C. (2013). Effects of inertia and satisfaction in female online shoppers on repeat-purchase intention: the moderating roles of word-of-mouth and alternative attraction. Managing Service Quality: An International Journal, 23(3), 168-187.

Marketing Türkiye (2018, 25 Haziran). Rakamlarla 2017 Türkiye e-ticaret istatistikleri. Erişim: https://www.marketingturkiye.com.tr/hab erler/rakamlarla-2017-turkiye-e-ticaret-istatistikleri/ , 11 Temmuz 2017.

Nayebzadeh, S., Abdolvand, M. A., Khajouei, F. (2013). Satisfaction, inertia, and customer loyalty in the varying levels of the zone of tolerance and alternative attractiveness. Journal of Basic and Applied Scientific Research, 3(3), 801-812.Oliver, R. L. (1999). Whence consumer loyalty?. The Journal of Marketing, 33-44.

Roland, R. (2001). The rise of e-service. Journal of Service Research, Cilt:3, Sayı: 4, Mayıs 2001, S.283-284.

Sadeh, E., Mousavi, L., Garkaz, M., Sadeh, S. (2011). The structural model of e-service quality, e-customer satisfaction, trust, customer perceived value and e-loyalty. Australian Journal of Basic \& Applied Sciences, 5(3),532-538.

Shankar, V., Urban, G., Sultan, F. (2002). Online trust: a stakeholder perspective, concepts, implications, and future directions. Journal of Strategic Information Systems, Vol. 11, pp. 325-44. 
Srinivasan, S. S., Anderson, R., Ponnavolu, K. (2002). Customer loyalty in e-commerce: an explanation of its antecedents and consequences. Journal of Retailing, Vol. 78, pp. 41-50. TÜiK (2018, 26, Haziran). Hane $\quad$ halkı bilişim $\quad$ teknolojileri kullanım araştırması. Erişim:
http://www.tuik.gov.tr/PreHaberBultenleri.do?id=24862

Wang, F., Head, M. (2002). E-tailing: an analysis of web impacts on the retail market. Journal of Business Strategies, Vol 19, No 1, ABI/INFORM Global, pp 73.

Wolfinbarger, G. (2003). Etailq: dimensionalizing, measuring and predicting e-tail quality. Journal Of Retailing, 79(3), s.83-198.

Wu, L. W. (2011). Satisfaction, inertia, and customer loyalty in the varying levels of the zone of tolerance and alternative attractiveness. Journal of Services Marketing, 25(5), 310-322.

Zeithaml, V. A., Parasuraman, A., Malhotra, A. (2000). A conceptual framework for understanding e-service quality: implications for future research and managerial practice. Working paper, Marketing Science Institute, Cambridge, MA.

Yang, Z., Jun, M., Peterson, R. T. (2004). Measuring customer perceived online service quality scale development and managerial implications. International Journal Of Operations \&, Production Management, 26(11), S. 1149-1174. 